\title{
Descrição da Larva de Último Estádio de Micrathyria pseudeximia Westfall (Odonata, Libellulidae)
}

\author{
Marina Schmidt Dalzochio \\ 1. Pesquisadora autônoma. Rua Terezina, 2305 - Bairro Tropical, CEP 85807-140 - Cascavel-PR-Brasil. e-mail: mahsdalzochio@gmail.com \\ EntomoBrasilis 2 (2): 54-57 (2009)
}

Resumo. A larva de último estádio de Micrathyria pseudeximia Westfall, 1992 é descrita e ilustrada a partir de material procedente de Cascavel, Paraná, Brasil. A caracterização do gênero com base nas larvas é ampliada.

Palavras-chave: Brachydiplacinae, imaturos, morfologia, sistemática

\section{Description of the Ultimate Stadium Larva of Micrathyria pseudeximia Westfall (Odonata, Libellulidae).}

Abstract. The larva of ultimate stadium of Micrathyria pseudeximia Westfall, 1992 is described and illustrated based on material collected in Cascavel Municipality, Paraná State, Brazil. The generic concept based on the larvae is amplified.

Key Words: Brachydiplacinae, immatures, morphology, systematics

$M$ icrathyria Kirby, 1889 tem sido alvo recente de estudos taxonômicos, tanto no que se refere a adultos (e.g. ASSIS \& COSTA, 1994; COSTA et al. 2002a) quanto a imaturos (SOUZA \& COSTA 2002, GARRÉ \& LOZANO 2007). O gênero inclui 46 espécies (GARRISON et al. 2006), das quais 18 têm suas larvas descritas (GARRÉ \& LOZANO 2007). No Brasil, são citadas 29 espécies, sendo que 14 já têm seus imaturos descritos: Micrathyria artemis Ris, 1911; Micrathyria atra (Martin, 1897); Micrathyria borgmeieri Santos, 1947; Micrathyria dydima (Selys in Sagra, 1857); Micrathyria hesperis Ris, 1911; Micrathyria hipodydima Calvert, 1906; Micrathyria longifasciata Calvert, 1909; Micrathyria mengeri (Ris, 1919); Micrathyria ocellata dentiens Calvert, 1909; Micrathyria pirassunungae Santos, 1953; Micrathyria spuria (Selys, 1900); Micrathyria stawiarskii Santos, 1953; Micrathyria tibialis Kirby, 1897 e Micrathyria ungulata Förster, 1907. Este trabalho amplia o conhecimento sobre os imaturos, com a descrição da larva de último estádio de Micrathyria pseudeximia Westfall, 1992.

SOUZA \& COSTA (2002) propuseram a separação das larvas das espécies de Micrathyria em dois grupos de acordo com o número de setas palpais presentes. As larvas de último estádio de $M$. pseudeximia pertencem ao grupo I, cuja principal característica é a presença de 8-9 setas palpais. Outras espécies incluídas nesse grupo são: $M$. pirassunungae, $M$. mengeri, $M$. tibialis, $M$. hesperis, $M$. spuria, $M$. longifasciata e $M$. stawiarskii.

\section{MATERIAL E MÉTODOS}

As larvas de $M$. pseudeximia foram coletadas no Lago Municipal de Cascavel, Estado do Paraná, Brasil, no período de junho de 2004 a junho de 2006, resultando em 65 exemplares de imaturos da espécie. Os imaturos de último estádio foram criadas em laboratório até a emergência dos adultos, segundo metodologia de COSTA et al. (2004b). Foram analisadas as exúvias de 14 adultos emergidos, sendo sete de machos e sete de fêmeas. A confirmação da identificação foi feita a partir de caracteres dos adultos com uso dos trabalhos de COSTA et al. (2002b) para o gênero e de WESTFALL (1992) e COSTA et al. (2002a) para a espécie. As medidas estão expressas em milímetros e foram tomadas sobre cinco exemplares aleatórios, sendo representados os limites mínimos e máximos observados. A fórmula mandibular é expressa segundo WATSON (1956). O material está depositado na coleção da Universidade Estadual do Oeste do Paraná, campus de Cascavel.

\section{RESULTADOS}

Micrathyria pseudeximia Westfall, 1992 (Figuras 1-5)

Medidas. Comprimento total (da região anterior do clípeo ao ápice do paraprocto): 12,80/15,80; comprimento dorsal da cabeça (da região anterior do clípeo à região posterior do occipício): 2,28/2,30; largura máxima da cabeça: 4,05/4,20; comprimento total das antenas: 2,13/2,25; comprimento dos antenômeros: I, 0,15/o,18; II, 0,20/0,23; III, 0,31/o,40; IV, 0,25/o,33; V, o,28/o,33; VI, 0,34/o,48; VII, 0,28/o,40; comprimento do premento: 3,24/3,48; comprimento do tórax: 2,70/3,80; comprimento da teca alar anterior: 4,75/5,00; comprimento da teca alar posterior: 4,35/4,70; comprimento dos fêmures: I, 2,83/3,00; II, 3,92/4,00; III, 4,40/4,90; comprimento das tíbias: I, 2,70/2,95; II, 3,10/3,62; III, 4,45/5,36; comprimento do abdômen: 6,03/7,70; largura máxima do abdômen: 4,55/4,81; comprimento do espinho lateral do oitavo segmento (da margem posterior do segmento até o ápice do espinho): 1,33/1,70; comprimento do espinho lateral do nono segmento (da margem posterior do segmento até o ápice do espinho): 1,08/1,30; comprimento do epiprocto: 0,78/0,98; largura basal do epiprocto: 0,68/0,83; comprimento do cerco: 0,47/0,50; comprimento do paraprocto: $1,75 / 2,08$.

Descrição. Coloração geral ocrácea, enegrecida nos 3/4 basais do 
sexto antenômero, e também com máculas na fronte e occipício Faixas dorsais enegrecidas no pronoto ao lado da linha mediana, nas pleuras torácicas, com anéis nos fêmures e tíbias, e com faixas dorsais no abdômen ao lado da linha mediana, a partir do sexto segmento. Porção distal dos espinhos laterais do oitavo e nono segmentos, e do epiprocto, acastanhados. Anel sub-distal nos paraproctos negro. Palpos labiais irregularmente salpicados de acastanhado e negro.

Cabeça mais larga que o tórax, com os olhos projetados lateralmente cerca de 1/10 da largura total. Margem posterior do occipício aproximadamente reta, ornada com espinhos e cerdas de tamanho variado. Antenas com sete antenômeros, sendo o sexto mais longo. Mandíbulas com (4) quatro incisivos, fórmula mandibular L1234 o ab/R1234 y abd. Lábio alcançando posteriormente o nível do segundo par de pernas, quando em repouso. Premento, na face interna, com 12 setas basais em cada lado, que aumentam e diminuem gradualmente de tamanho ao longo da fileira, curvada regularmente; região sub-distal com setas diminutas em mosaico, ápice com 2 setas e margens distais com 5 a 7 setas, em cada lado; região articular dos palpos com 3 setas, em cada lado. Palpos labiais com 9 setas cada, mais a garra móvel; parte basal da face interna provida de 5 a 7 espinhos diminutos; crenulações em número de 7 , desde mais entalhadas até obsoletas, a partir da margem superior ou externa, e armadas usualmente de 4 setas cada, sendo a primeira seta o dobro da segunda, que é o triplo da terceira, e a quarta diminuta. Margem inferior ou interna com 8 a 10 setas; face externa lisa.

No tórax, as tecas alares são divergentes, alcançando o nível do sexto segmento. Pernas providas de espinhos nos fêmures, de espinhos e cerdas nas tíbias, e de cerdas longas e negras na porção distal da face dorsal dos fêmures similares às encontradas nas larvas de Nephepeltia Kirby, 1889, como apresentam CARVALHO et al. (2002).

Abdômen ovalado, mais largo ao nível do sexto segmento. Face dorsal com uma banda de cerdas de cada lado, mais definidas e ultrapassando a margem posterior a partir do sexto segmento, coalescentes ao longo da linha mediana a partir do sétimo segmento, bem como fileira de espinhos pré-marginais também nítida a partir do sexto segmento. Oitavo e nono segmentos providos de espinhos laterais, sendo o do oitavo cerca de 1,5 vezes maior que o comprimento médio dorsal do segmento, e o do nono mais de 2 vezes o comprimento médio dorsal do segmento. Face ventral coberta com espinhos, nitidamente a partir do sexto segmento.

Epiprocto subtriangular, abaulado medianamente e deprimido lateralmente em direção ao ápice, e provido de dois espinhos no terço distal da face dorsal, um de cada lado da linha mediana; ápice discretamente curvado para baixo; bordas laterais com cerdas dispostas regularmente. Cercos constritos em direção ao ápice, distalmente curvados para baixo; margem externa reta, com cerca da metade do comprimento do epiprocto, e quatro vezes menores que o comprimento dos paraproctos. Paraproctos aproximadamente duas vezes mais longos que o epiprocto, de seção transversal triangular, retos e afilados para o ápice; espinhos mais concentrados nos vértices e fileiras de cerdas nas margens mesal e internas.

Material examinado. Brasil. Paraná: Cascavel (Lago Municipal): 21.i.2005 (emergência 22.i.2005) um macho, G.S. Andrade \& M.S. Dalzochio leg., 21.i.2005(emergência 05.ii.2005) um macho, G.S. Andrade \& M.S. Dalzochio leg., 21.i.2005 (emergência 19.iii.2005) uma fêmea, G.S. Andrade \& M.S Dalzochio leg., 19.x.2005, (emergência 01.xi.2005) uma fêmea, G.S. Andrade \& M.S. Dalzochio leg., 19.x.2005, (emergência 05.xi.2005) um macho, G.S. Andrade \& M.S. Dalzochio leg., 19.x.2005, (emergência 06.xi.2005) uma fêmea, G.S. Andrade \& M.S. Dalzochio leg., 19.x.2005, (emergência 09.xi.2005) um macho, G.S. Andrade \& M.S. Dalzochio leg., 19.x.2005, (emergência 10.xi.2005) um macho, G.S. Andrade \& M.S. Dalzochio leg., 19.x.2005, (emergência 17.xi.2005) uma fêmea, G.S. Andrade \& M.S. Dalzochio leg., 19.x.2005, (emergência 20.xi.2005) uma fêmea, G.S. Andrade \& M.S. Dalzochio leg., 30.xi.2005, (emergência 12.xii.2005) um macho, G.S. Andrade \& M.S. Dalzochio leg., 30.xi.2005, (emergência 04.ii.2006) uma fêmea, G.S. Andrade \& M.S. Dalzochio leg., 7.iii.2006, (emergência 16.iii.2006) um macho, G.S. Andrade \& M.S. Dalzochio leg., 7.iii.2006, (emergência 16.iii.2006) uma fêmea, G.S. Andrade \& M.S. Dalzochio leg. O material está depositado na coleção da Universidade Estadual do Oeste do Paraná, campus de Cascavel.

Comentários. Observou-se nítida variação de coloração nas larvas e também nas exúvias de machos e fêmeas emergidos, sendo mais pigmentadas com máculas as destas últimas. Um dos exemplares examinados apresenta 13 setas prementais à direita.

Habitat. As larvas foram coletadas em lago artificial rico em matéria orgânica em decomposição, geralmente associadas à vegetação marginal e em lagoas temporárias ricas em detritos vegetais em decomposição que se formavam nos períodos chuvosos.

\section{DISCUSSÃO}

Os padrões morfológicos que definem Micrathyria são, aqui, contestados, já que o imaturo de $M$. pseudeximia difere significativamente do padrão do gênero por possuir espinhos laterais, tanto do oitavo quanto do nono segmento, muito maiores que o comprimento médio dorsal dos mesmos e cerdas dos fêmures do padrão citado para Nephepeltia (CARVALHO et al. 2002). Inicialmente, a larva foi confundida com aquelas de Tramea Hagen, 1861 por assemelhar-se muito com os caracteres citados na chave por CARVALHO et al. (2002). A dúvida só foi esclarecida após criação de larvas e obtenção de imagos, que são identificados claramente como $M$. pseudeximia conforme características citadas nos trabalhos de WESTFALL (1992) e COSTA et al. (2002a).

A presença de cerdas femorais em $M$. pseudeximia contesta CARVALHO et al. (2002) em relação à utilização desse caráter como diferencial entre imaturos de Micrathyria e Nephepeltia. Já comparações entre imaturos de Micrathyria e Nephepeltia berlai Santos, 1953 contradizem o caráter citado por COSTA et al. (2004a) como diferencial entre os gêneros. Os olhos quadrados e eqüidistantes, considerados para Nephepeltia, não aparecem em $N$. berlai. Estes se apresentam alongados e próximos, como considerados para Micrathyria.

Apesar de diferir substancialmente dos demais pelo comprimento dos espinhos laterais, seguindo padrões citados na chave de SOUZA \& COSTA (2002), o imaturo de $M$. pseudeximia estaria próximo de M. spuria, por possuir mandíbulas esquerda e direita com dois e três molares, respectivamente, e esta última com dente adicional, bem como pelos cercos desenvolvidos semelhantes ao epiprocto. Com a avaliação dos caracteres diagnósticos das espécies do grupo I (setas pré-mentais e setas palpais), pode-se observar que $M$. pseudeximia separa-se de M. spuria, pelo número de setas palpais. Com isso, $M$. pseudeximia estaria mais próxima de $M$. stawiarskii, ambas diferindo de $\mathrm{M}$. longifasciata por apresentarem doze setas pré-mentais. Já essas, entre si, diferem pela presença de dente adicional extra (x) em $M$. stawiarskiii.

\section{AGRADECIMENTOS}

Ao Conselho Nacional Desenvolvimento Científico e Tecnológico (CNPq), aos Profs. Drs. Luis Francisco Angeli Alves e Gabriel Simões de Andrade (Universidade Estadual do Oeste do Paraná, Cascavel), pelas facilidades concedidas no desenvolvimento e elaboração deste trabalho e a Patrícia Milano pelas ilustrações. 

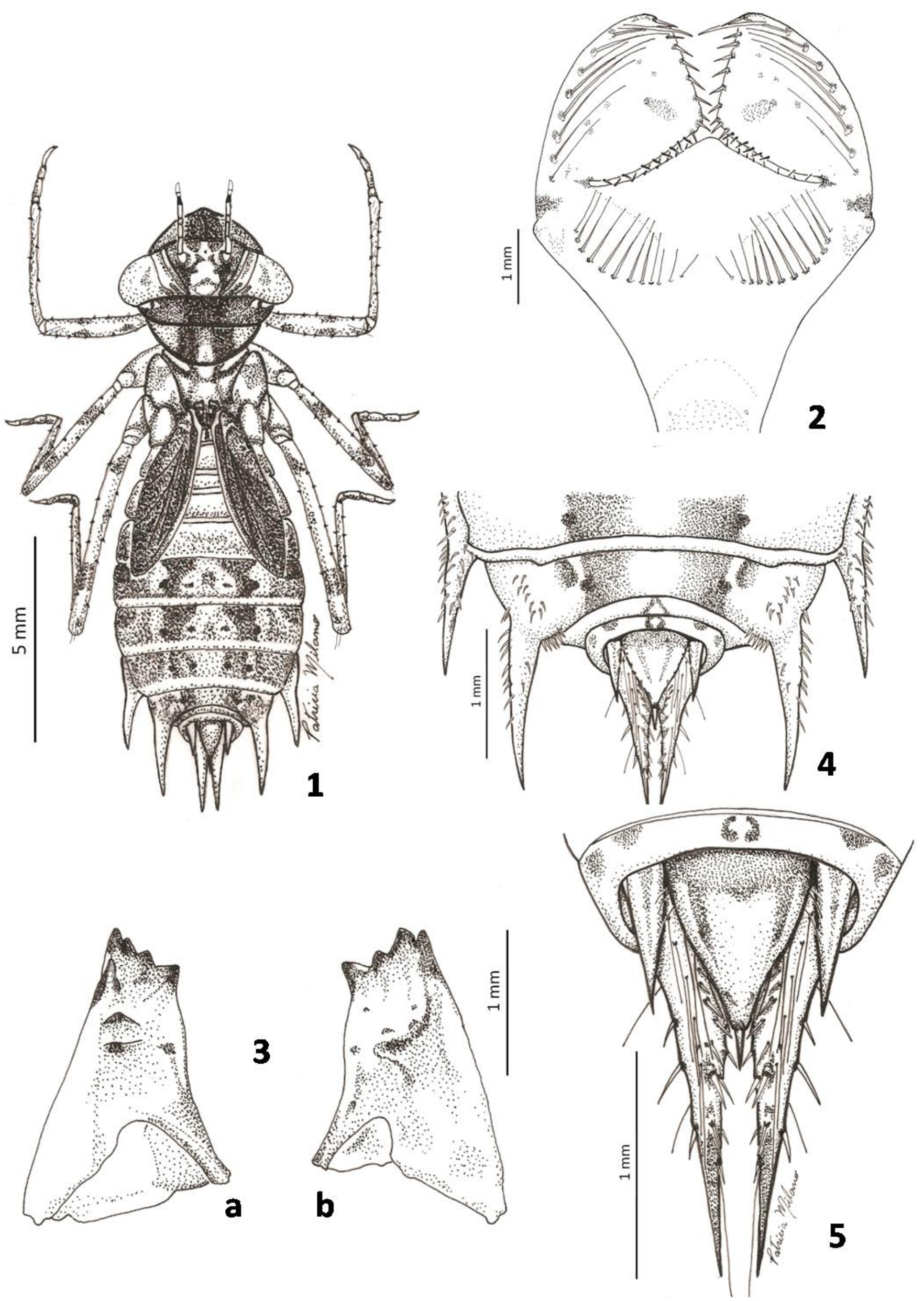

Figuras 1- 5: Micrathyria pseudeximia: (1) Aspecto geral da exúvia de último estádio. (2) Lábio. (3) Mandíbulas (a - direita, b- esquerda). (4) Espinhos laterais. (5) Apêndices abdominais. 


\section{REFERÊNCIAS}

Assis, C.V. \& J.M. Costa. 1994. Seis novas larvas do gênero Micrathyria Kirby e notas sobre a distribuição no Brasil (Odonata, Libellulidae). Revista Brasileira de Zoologia, 11 (2): 195-209.

Carvalho, A.L.; P.C. Werneck-De-Carvalho \& E.R. Calil. 2002. Description of the larvae of two species of Dasythemis Karsch, with a key to the genera of Libellulidae occurring in the states of Rio de Janeiro and São Paulo, Brazil (Anisoptera). Odonatologica, 31 (1): 23-33.

Costa, J.M.; A.N. Lourenço \& L.P. Vieira. 2002a. Micrathyria pseudhypodidyma sp. n. (Odonata: Libellulidae), com Chave das Espécies do Gênero que Ocorrem no Estado do Rio de Janeiro. Neotropical Entomology, 31 (3): 377-389.

Costa, J.M.; A.N. Lourenço \& L.P. Vieira. 2002b. Chave de identificação para imagos dos gêneros de Libellulidae citados para o Brasil - Comentários sobre os gêneros (Odonata: Anisoptera). Entomología y Vectores, 9 (4): 477-504.

Costa, J. M.; L. O. I. Souza \& B. B. Oldrini. 2004a. Chave para Identificação das Famílias e Gêneros das larvas de Odonata do Brasil: Comentários e Registros Bibliográficos (Insecta: Odonata). Publicações Avulsas do Museu Nacional, 99: 3-42.

Costa, J.M.; J. Pujol-Luz \& L. L. P. B. Régis. 2004b. Descrição da larva de Zenithoptera anceps (Odonata, Libellulidae).

Como citar este artigo:

M.S.Dalzochio,2009. DescriçãodaLarvadeÚltimoEstádiodeMicrathyria pseudeximiaWestfall(Odonata,Libellulidae).EntomoBrasilis,2(2):54-57. www.periodico.ebras.bio.br/ojs
Iheringia, Série Zoologia, 94(4): 421-424.

Garrison, R. W., N. von Ellenrieder \& J. A. Louton. 2006. Dragonflies Genera of The New World: An Illustrated and Annotated Key To the Anisoptera. The Johns Hopkins University Press, Baltimore, 384 pp.

Garré, A. \& F. Lozano. 2007. Descripción del último estadio larval de Micrathyria ungulata (Odonata: Libellulidae). Revista de la Sociedad Entomológica Argentina, 66 (1-2): 5-9, 2007.

Souza, L.O.I. \& J.M. Costa. 2002. Descrição de três larvas de Micrathyria Kirby, 1889, com chave para identificação das larvas conhecidas das espécies brasileiras (Odonata, Libellulidae). Arquivos do Museu Nacional, 60 (4): 321-331.

Watson, M.C. 1956. The utilization of mandibular armature in taxonomic studies of anisopterous nymphs. Transactions of the American Entomological Society, 81 (3-4): 155-205.

Westfall, M.J. 1992. Notes on Micrathyria, with descriptions of M. pseudeximia sp. n., M. occipita sp. n., M.dunklei sp. n. and $M$. divergens sp. n. (Anisoptera: Libellulidae). Odonatologica, 21 (2): 203-218.

Recebido em: 19/05/2009

Aceito em: 23/07/2009

$$
* * * * * * * * * * * * *
$$

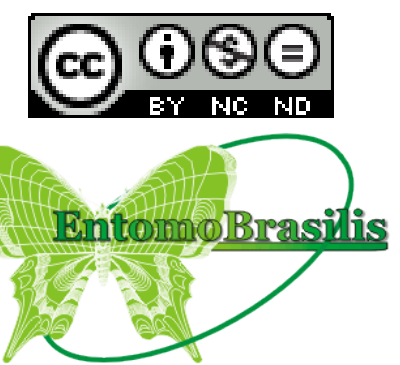

